\title{
Lessen uit een provinciaal windbeleid?
}

\author{
AUTEUR Reinout Debergh \\ FOTOGRAFIE Jeff Kubina
}

\section{In vergelijking met haar buurregio's loopt Vlaanderen achter met realiseren van windenergieprojecten. Dit zette de provincie Oost-Vlaanderen ertoe aan om een provinciaal windbeleid op te starten met als basis een ruimtelijke visie.}

Sinds enkele jaren is er sprake van een grote dynamiek op de Vlaamse 'windmarkt'. Vanuit een toenemende aandacht voor het klimaat en de eindigheid van fossiele brandstoffen, is een enorme politieke maar ook financiële druk ontstaan om tot een grotere productie van groene stroom te komen. On-shore windenergie moet hier een belangrijk deel op zich gaan nemen. Er wordt dan ook gezocht naar mogelijke plaatsen voor windturbines, waarvoor ontwikkelaars nu al om vergunningen strijden.

In een dichtbebouwde regio als Vlaanderen met versnipperde structuren en kenmerkende lintbebouwingen kan het plaatsen van een windturbine echter niet zomaar. De productie van windenergie is namelijk niet de enige sector die aanspraak maakt op de schaarse beschikbare ruimte. Windmolens kunnen de visuele kwaliteit van een landschap sterk doen dalen, met als resultaat een chaotisch en industrieel aanvoelende omgeving. Ook de leefkwaliteit van omwonenden kan bij een ongepaste inplanting in het gedrang gebracht worden en tenslotte is ook het veiligheidsaspect een niet te verwaarlozen factor.

\section{Aanleiding}

Ondanks de omzendbrief die de Vlaamse overheid in 2000 opstelde en waarmee zij een aantal randvoorwaarden voor de inplanting van windturbines vastlegde, kwamen slechts weinig projecten tot realisatie. Vanaf 2005 werd steeds duidelijker dat de onverenigbaarheid met de ruimtelijke bestemming de inplanting van windturbines in de weg kon staan. Voor het inplanten van een windturbinepark was namelijk steeds een bestemmingswijziging noodzakelijk via een ruimtelijk uitvoeringsplan (RUP). De opmaak van deze plannen, waarvan de bevoegdheid voornamelijk op het niveau van het Vlaamse Gewest lag, verliep echter slechts met mondjesmaat. Bovendien gebeurde dit niet in een breder kader, maar ad hoc, zonder een samenhangende visie, met alle gevolgen voor het lokale draagvlak. Vanaf 2005 werden de provincies meer en meer met vragen geconfronteerd. Wanneer een wijziging van de omzendbrief in 2006 voor hen een grotere rol mogelijk maakt binnen het planningsgebeuren, beslisten de provincies West- en Oost-Vlaanderen dan ook om in te stappen in het 'windenergieverhaal', zowel voor wat betreft de uitbouw van een maatschappelijk draagvlak, als voor het planologisch inpassen windturbines.

Reeds bij de opstart van het provinciale beleid was duidelijk dat het vergroten van mogelijkheden voor windturbines enkel kon indien men dit zou kaderen in een duidelijke ruimtelijke structuurvisie. Er kon niet verder worden gegaan met het ad hoc opmaken van ruimtelijke uitvoeringsplannen zoals dat in het verleden was gebeurd. Zowel de provincie West- als Oost-Vlaanderen startte dan ook met de opmaak van ruimtelijke beleidskaders.

In het geval van de provincie Oost-Vlaanderen werd reeds in de beginfase geopteerd om dit beleidskader deel te laten uitmaken van het provinciaal ruimtelijk structuurplan omwille van de grotere democratische gedragenheid en de juridische kracht binnen de provinciale en gemeentelijke planprocessen. De opmaak van het beleidskader gebeurde door de provinciale dienst ruimtelijke ordening. Voor het begeleiden van de opmaak werd een provinciale windwerkgroep opgericht, bestaande uit vertegenwoordigers van de betrokken provinciale diensten.

In tegenstelling tot het beleidskader van de provincie West-Vlaanderen - dat enkel tot doel had een aantal zoekgebieden op macro-niveau aan te geven - was het ambitieniveau van de provincie Oost-Vlaanderen zeer hoog.

Het provinciaal beleidskader moest duidelijkheid verschaffen aan burgers, gemeenten, bedrijven en ontwikkelaars over de randvoorwaarden, beleidskeuzes en bevoegdheden met betrekking tot windenergie in Vlaanderen, en moest door middel van een ruimtelijke structuur aangeven waar plaats was voor groot-, midden- en kleinschalige turbines.

\section{Inplantingsmogelijkheden voor windturbines}

Een belangrijke lijn in het Oost-Vlaamse beleidskader is de wil om positief om te gaan met windturbines. Deze worden beschouwd als elementen met een nut op globale schaal die - mits een goede 
inplanting - een landschappelijke meerwaarde kunnen creëren door het accentueren van structuren en de vorming van nieuwe windlandschappen. Hiermee wordt ook afgestapt van de sterk defensieve visie in de Vlaamse omzendbrieven die tot dan toe vooral aangaf waar windturbines moesten geweerd worden en die uitging van een 'camouflage' binnen reeds verstoorde, visueel vervuilde omgevingen.

De kern van het provinciaal beleidskader bestaat uit de ruimtelijke visie waarin wordt aangegeven waar het inplanten van groot- en middenschalige turbines met een masthoogte van meer dan vijftien meter wenselijk is. Deze ruimtelijke visie gaat uit van de creatie van een nieuwe landschapslaag (het Oost-Vlaamse windlandschap) bestaande uit en gevormd door groot- en middenschalige windturbines.

In het provinciaal beleidskader wordt de realisatie van dit windlandschap beoogd door het optimaal benutten van de mogelijkheden binnen zogenaamde 'potentiële inplantingslocaties'. Deze locaties zijn het resultaat van een screening van het volledige Oost-Vlaamse grondgebied aan de hand van positieve aanknopingspunten (steden, grootschalige lijninfrastructuren en bedrijvigheid), uitsluitingscriteria (speciale beschermingszones, natuurgebieden en woongebieden) en een landschappelijke structurering op macroniveau binnen de richtlijnen en gebiedsgerichte visies van het bestaande provinciaal ruimtelijk structuurplan.

Voor het opmaken van een ruimtelijke structuur (zie figuur1) werden twee basisprincipes vooropgesteld: de maximale benutting van geschikte zones en het bekomen van sterke visuele accenten door middel van concentratie en contrast. Concentratiezones met een dynamische aanblik worden daarbij afgewisseld met visueel landschappelijke rustzones.

\section{Windmolens kunnen de visue- le kwaliteit van een landschap sterk doen dalen.}

\begin{abstract}
Als overkoepelende structuren die voor een samenhang dienen te zorgen binnen de volledige provincie en de kern vormen van de nieuwe 'landschapslaag', werden twee structuren geselecteerd: de centrale plaatsen (steden, economische knooppunten en stedelijke netwerken) en de poorten en slagaders (transportcorridors en havens).

Deze grote structuren werden vervolgens genuanceerd en gedifferentieerd aan de hand van de bestaande landschappelijke structuren. Het is bijvoorbeeld evident dat andere aandachtspunten gelden in een zeer open polderlandschap als in een gesloten landschap. Zelfs indien uitgegaan wordt van de creatie van een bijkomende landschapslaag kan de wisselwerking tussen deze nieuwe laag en de bestaande landschappelijke structuren niet onderschat worden. Er werd in het bijzonder gefocust op schaaleffecten en visuele oriëntatie.

Het deelgebiedenbeleid uit het provinciaal ruimtelijk structuurplan was de basis voor het voorstellen van specifieke inplantingsvormen (lineair, groepsgewijs, solitair) en ruimtelijke randvoorwaarden.
\end{abstract}
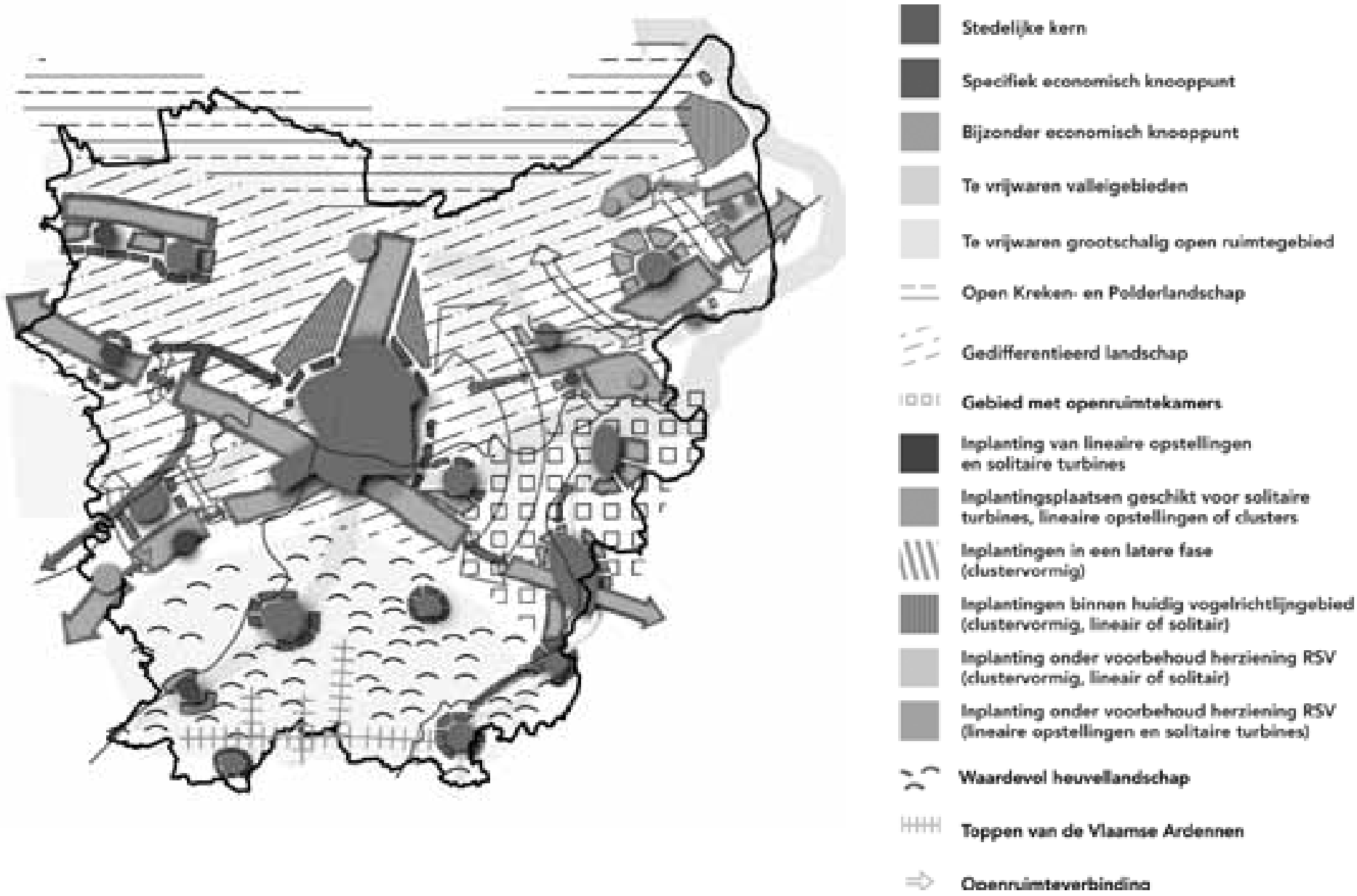

Potentiële inplantingslocaties voor windmolens in de regio Gent

(Bron: Provincie Oost-Vlaanderen, 2009) 


\section{Lessen uit openbaar onderzoek}

Bij de beslissing tot opmaak van het beleidskader werd geopteerd om het proces zo open mogelijk te voeren om te komen tot een zo groot mogelijke consensus. In de loop van het planproces werden alle betrokken administraties op lokaal, provinciaal en gewestelijk niveau uitvoerig geïnformeerd en bevraagd. In de winter van 2008-2009 werd het debat vervolgens geopend voor de bevolking. Het onderzoek werd zo ruim mogelijk bekendgemaakt via het internet, de regionale radio en televisie, en de kranten. Daarnaast werden ook drie infoavonden georganiseerd.

Uit dit openbaar onderzoek, in principe het eerste met betrekking tot de ruimtelijk inplanting van windturbines in Vlaanderen, kan heel wat geleerd worden. Een eerste vaststelling is dat de voorgestelde visie een ruim draagvlak heeft bij de bevolking. De plaatsing van turbines nabij de grote lijninfrastructuren heeft duidelijk de voorkeur boven het plaatsen van turbines in de open ruimtegebieden. De grootste kritiek werd geuit op de aangeduide potentiële inplantingslocaties op de randen van de open ruimtegebieden. In tegenstelling tot andere landen waar vaak wordt gepleit om turbines in open ruimtegebieden met beperkte bewoning te plaatsen, wordt de schaarse open ruimte binnen Oost-Vlaanderen als te waardevol aanzien. Tegenover dit grote draagvlak voor bundeling staan echter de bezwaren van bewoners van de stadsranden, die in deze bundeling een verdere versterking van hun reeds verstedelijkende leefomgeving zien. Deze bewoners, maar ook de gemeentebesturen van deze randgemeenten, pleiten eerder voor een spreiding van de lasten.

Opmerkelijk is dat een grotere landschappelijke waarde wordt toegeschreven aan de eigen omgeving. Een versnipperd open ruimtegebied kan zo door de omwonenden als uitzonderlijk waardevol worden omschreven.

Binnen het openbaar onderzoek kon bovendien een opmerkelijke regionale spreiding van het aantal bezwaren teruggevonden worden, veroorzaakt door het al dan niet aanwezig zijn van lokale actiegroepen. Deze actiegroepen, nagenoeg steeds ontstaan in het kader van een concreet windproject of een eerder gevoerd planningsproces voor bijvoorbeeld bedrijvigheid, zorgen niet enkel voor een sterke lokale mobilisatie. Ook de gebruikte argumentatie bij de bezwaarindieners is verschillend. In het geval van een actiegroep verschuift het landschappelijke argument naar het aspect geluids- en slagschaduwhinder, met de nadruk op geluidshinder. De oorzaak voor deze verschuiving kan gezocht worden in de concretere betrokkenheid bij projecten (geluidsen slagschaduwhinder bevinden zich op een concreter schaalniveau dan het opmaken van een ruimtelijk landschappelijke visie). Aangezien in de buurlanden vaak afstandsregels gelden voor windturbines ten

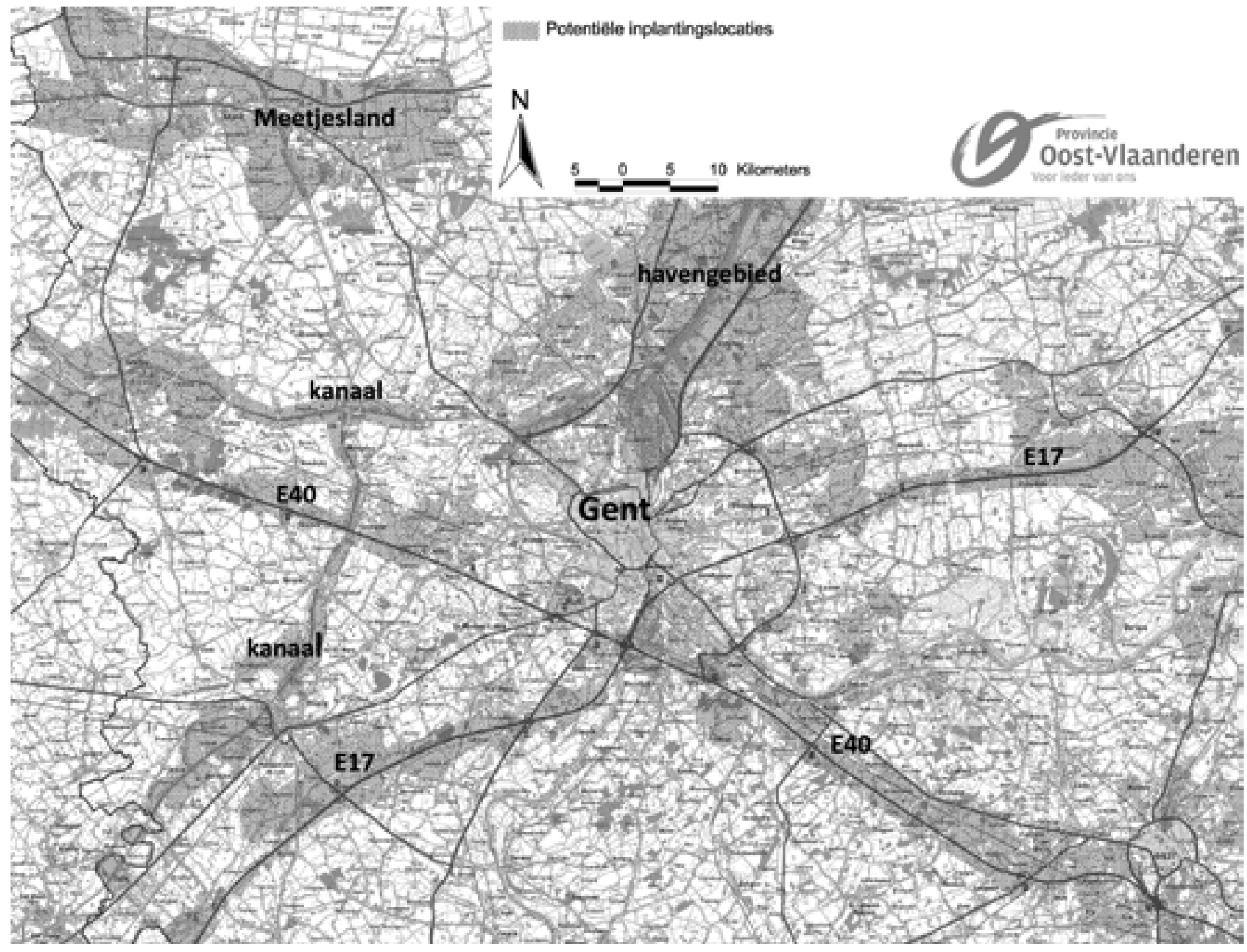


opzichte van woningen en dit in Vlaanderen niet rechtstreeks het geval is, wordt door de actiegroepen ook specifiek strategisch op dit aspect gefocust, waarbij vaak gebruik wordt gemaakt van een aantal studies rondom de eventuele impact van geluidshinder op de gezondheid. Opmerkelijk is de rol die deze actiegroepen kunnen spelen in het verspreiden van angst (uitvergroten van problemen tot op grote afstand van de potentiële gebieden). Bovendien is ook in grote mate een sociale druk terug te vinden in gebieden waar een actiegroep actief is, wat zich uit in het opstarten van petities of gezamenlijk ingediende bezwaarschriften, vaak met standaardbrieven. In een aantal gevallen diende nagenoeg een volledige straat bezwaar in, zelfs zonder concreet projectvoorstel in de omgeving.

Een rode lijn door het openbaar onderzoek was de vraag naar een betere sturing van windprojecten en een betere verdeling van de lusten en de lasten. Omwonenden zijn sneller geneigd akkoord te gaan met een project waar ze zelf bij betrokken worden. De invulling van een gebied door een projectontwikkelaar, waarbij enkel de grondeigenaar en de ontwikkelaar zelf voordeel hebben, wordt aanzien als sterk onrechtvaardig. In een aantal gevallen werd letterlijk gesteld dat

\section{Er resten echter meer vragen dan antwoorden.}

dergelijke projecten profiteren van de wind en het landschap van de gemeenschap, maar het financieel voordeel voor zich houden en de hinder laten aan de omwonenden. Verschillende bezwaarindieners wensen een diepere inspraak en participatie bij concrete projecten in hun omgeving.

De bezorgdheid voor een 'top down' inplanting van windturbines komt ook naar voor in de adviezen van de gemeentebesturen. Ook vanuit de lokale besturen wordt gepleit voor meer inspraak, niet zozeer bij de opmaak van de ruimtelijke visie en de aanduiding van potentiële inplantingslocaties op provinciaal niveau, maar voornamelijk bij concrete projecten (specifieke locatiekeuze, inplantingstypologie). Ook hier komt het verhaal van de lusten en lasten terug. Lokale besturen kunnen in veel gevallen akkoord gaan met windturbines als voorziening van openbaar nut waar in geparticipeerd kan worden, maar staan afkerig tegen zuiver commerciële projecten.

\section{Impact van een planproces}

Op 17 juni 2009 werd het provinciale beleidskader uiteindelijk goedgekeurd door de Vlaamse minister bevoegd voor ruimtelijke ordening. Sindsdien is het een onlosmakelijk deel van het provinciale ruimtelijk structuurplan. Hierdoor vormt het de basis voor verdere provinciale planprocessen en de beoordeling van gemeentelijke planprocessen. Daarnaast wordt het beleidskader, alhoewel niet rechtstreeks bindend, momenteel als leidraad gebruikt bij het verlenen van concrete milieuen stedenbouwkundige vergunningen.

Het eindresultaat van een planproces kan in dit geval misschien echter minder belangrijk worden genoemd dan het proces op zich. In de eerste plaats heeft dit een stroomversnelling veroorzaakt voor de implementatie van en de visie op on-shore windenergie in Vlaanderen.
Al tijdens het planproces is het indienen van concrete projectvoorstellen en vergunningsaanvragen opvallend toegenomen. Het planproces heeft windenergie van een marginaal ruimtelijk verschijnsel opgewaardeerd naar een standaard afwegingselement binnen de verdere provinciale planprocessen en de beoordeling van de gemeentelijke planprocessen.

Ook op het vlak van de kleinschalige windturbines was het planproces van de provincie Oost-Vlaanderen cruciaal. Hiervoor bestond geen enkel beleid. De visie vanuit de provincie was de directe aanleiding en inspiratiebron voor een Vlaamse omzendbrief.

Het planproces in Oost-Vlaanderen en in mindere mate de beleidsvisie uit West-Vlaanderen zetten ook de provincies Antwerpen en Limburg ertoe aan om na te denken over de plaats van windturbines in hun landschappen. Ook hier worden momenteel beleidskaders opgemaakt. Door het planproces is ook heel wat expertise verzameld. Het openbaar onderzoek gaf waardevolle informatie en insteken naar een verder windbeleid.

Bij het beëindigen van het planproces is de juridische slagkracht van het beleidskader echter veel kleiner dan oorspronkelijk gedacht. In het begin werden de provinciale overheden nog gezien als een zeer geschikt overheidsniveau voor het opmaken van ruimtelijke uitvoeringsplannen voor windturbines. De opmaak van een provinciaal beleidskader werd aangemoedigd als een nuttig middel om via een ruimtelijke visie tot een betere inplanting in Vlaanderen te komen. De provincies hadden als tussenniveau een bevoorrechte plaats binnen het beleidslandschap om zowel een overzicht te kunnen bewaren en ad hoc beslissingen te vermijden als om planningsprocessen te kunnen voeren met voldoende terreinkennis.

Sinds maart 2009 is de situatie echter volkomen veranderd. Door een wijziging in het Vlaamse decreet op de ruimtelijke ordening is in nagenoeg alle gevallen een planproces overbodig geworden. Alle agrarische gebieden kwamen namelijk direct in aanmerking voor vergunningsverlening. Aangezien het beleidskader in principe niet bindend is bij deze vergunningsverlening, deed dit zijn juridische slagkracht quasi volledig te niet en is er in principe geen bindend beleid dat de inplanting van windturbines in ongewenste gebieden of in ongeschikte inplantingstypologieën kan voorkomen. Het inplanten van windturbines werd uit het directe werkveld van de ruimtelijke planning weggehaald en zo goed als volledig afhankelijk gemaakt van een ad hoc vergunningsbeleid op gewestelijk niveau. De sturende invloed die een overheid door middel van een aangepaste planning met specifieke voorschriften kon uitoefenen is hierdoor in het grootste gedeelte van Vlaanderen verloren gegaan. Bovendien heeft de decreetwijziging de concurrentie tussen de ontwikkelaars aangewakkerd. Het gevecht om de schaarse ruimte is bikkelhard geworden, een projectvoorbereiding een race tegen de klok. Het loont steeds minder om in te zetten op een van onderuit opgebouwde projectontwikkeling met verregaande participatie en inspraak.

\section{Meer vragen dan antwoorden}

Zoals uit voorgaande blijkt, werd door het Oost-Vlaamse windproject heel wat in beweging gebracht en werd heel wat bijkomend inzicht verworven. Er resten echter meer vragen dan antwoorden. 
Het inplanten van windturbines in Vlaanderen is niet langer het eenvoudige verhaal van een aantal jaren geleden waar de goedbedoelende projectontwikkelaar op zoek ging naar een geschikte locatie, draagvlak bij de bevolking en de nodige vergunningen, een verhaal waar de overheid makkelijk kon op inspelen door procedures te vereenvoudigen, geschikte gebieden aan te geven en door het voeren van sensibiliseringsacties. Het is nu een complex samenspel geworden van verschillende concurrentiële spelers, waarbij niet zozeer aanmoediging, dan wel sturing en kwaliteitscontrole van projecten de belangrijkste uitdagingen worden voor de verschillende overheden.

Maar op welke manier kan dit in de praktijk gebracht worden? Hoe wordt een landschappelijk gewenste structuur in de praktijk gerealiseerd en bewaard? Hoe kan een billijke verdeling van de lusten en lasten tot stand worden gebracht? Hoe wordt concurrentie gereguleerd? Op welke manier wordt het precaire draagvlak behouden en versterkt? Hoe omgaan met windrecht? En misschien nog belangrijker: hoe is dit alles juridisch te onderbouwen?

Het is duidelijk dat een antwoord de inbreng vereist van alle overheden, zowel de Vlaamse, de provinciale als de lokale. De gedragen ruimtelijke beleidskaders op provinciaal niveau zijn hierin van groot belang. Ze geven echter geen eindconclusie maar zijn eerder een eerste stap naar een integraal windbeleid, waarin zowel ruimte, milieu, veiligheid energie, economie als sociale aspecten een plaats kunnen vinden.

\section{Reinout Debergh (reinout.debergh@oost-vlaanderen.be) is ruimtelijk planner binnen de dienst Ruimtelijke Planning van de provincie Oost-Vlaanderen en opsteller van het provinciaal beleidskader windturbines.}

\author{
Literatuurselectie \\ Provincie Oost-Vlaanderen (2009) Provinciaal beleidskader Windturbines: \\ Addendum aan het PRS. Gent. www.oost-vlaanderen.be/windenergie \\ Dewael, P, Stevaert, S., Dua, V. en Sauwens, J. (2000). Omzendbrief: \\ EME/2000.01 Afwegingskader en randvoorwaarden voor de inplanting van \\ windturbines. Belgisch Staatsblad 1 september 2000, P 30220 - 30229 \\ Leterme,Y., Van Mechelen, D. en Peeters, K. (2006). Omzendbrief: \\ EME/2006/01 - RO/2006/02 Afwegingskader en randvoorwaarden voor de \\ inplanting van windturbines. Belgisch Staatsblad 24 oktober 2006, p 56705 - \\ 56713. \\ Van Mechelen, D. en Crevits, H. (2009). Omzendbrief LNE/2009/01 - \\ RO/2009/01 Beoordelingskader voor de inplanting van kleine en middelgrote \\ windturbines. Brussel, $15 \mathrm{pp}$.
}

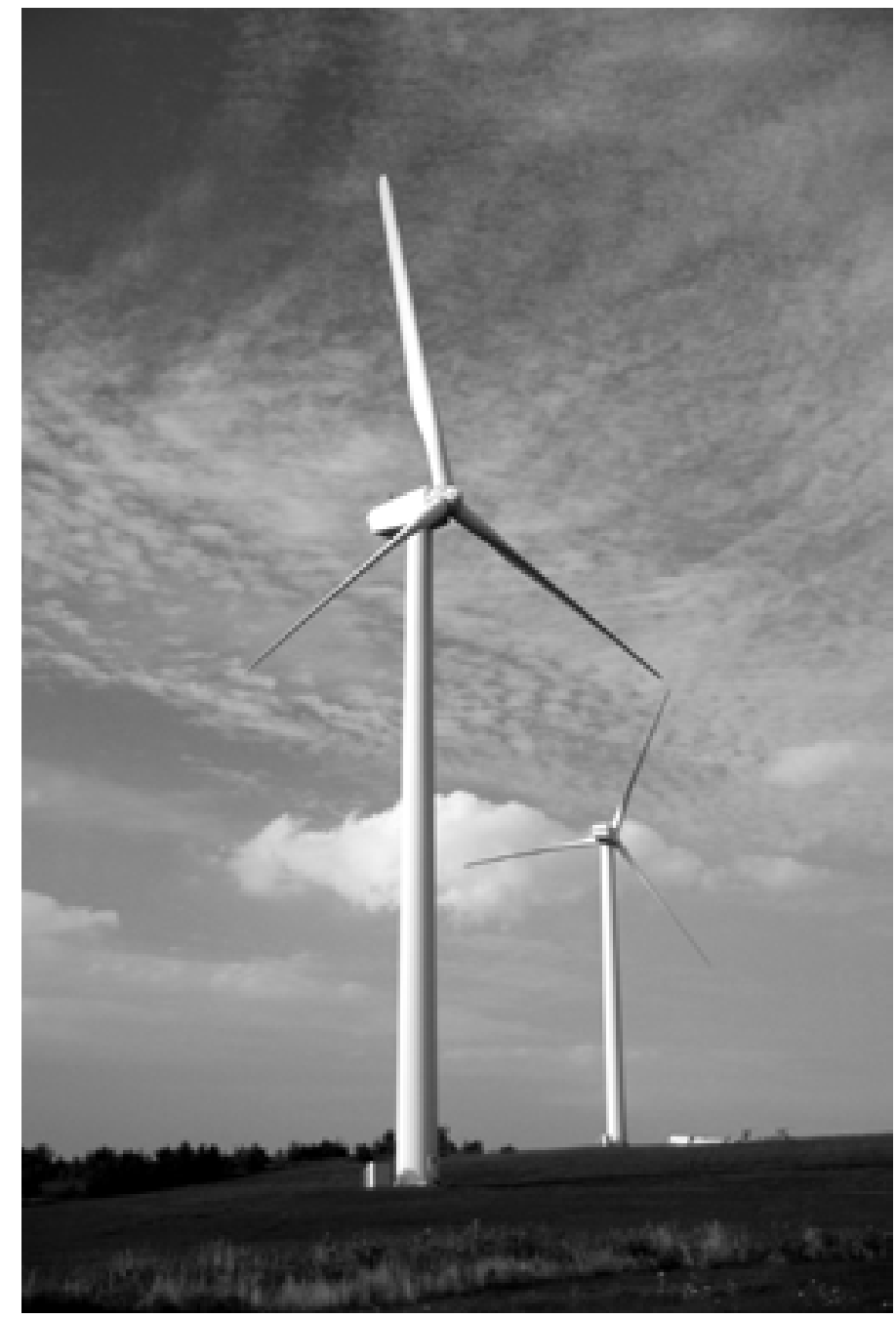

